\title{
New Technique to Accelerate Gas Production on CBM Through Use of Sacrifice Well
}

\author{
Leksono Mucharam ${ }^{1}$, Silvya Rahmawati ${ }^{1} \&$ Rafael Purba ${ }^{1}$ \\ ${ }^{1}$ Petroleum Engineering Department, Institut Teknologi Bandung, Indonesia \\ Correspondence: Silvya Rahmawati, Petroleum Engineering Department, Institut Teknologi Bandung, Ganesha \\ St. Nr 10 Labtek IV, West Java, Bandung, Indonesia Tel: 62-22-2506282. E-mail: sdr@tm.itb.ac.id
}

Received: December 12, 2017

Accepted: December 22, 2017 Online Published: December 27, 2017

doi:10.5539/mas.v12n1p86

URL: https://doi.org/10.5539/mas.v12n1p86

The research is financed by P3MI Research Fund ITB Bandung Indonesia.

\begin{abstract}
Coal Bed Methane (CBM) is an unconventional resource that shows great promise, particularly in Indonesia, whose CBM reservoir is relatively thick. Gas reserves of CBM are estimated at 450 TSCF in Indonesia, which makes it, the 6th largest CBM-containing country in the world. However, regulatory and technical limitations slow the progression of the exploitation of this resource. One of the fundamental technical problems is related to the length of gas production due to the duration of the dewatering time. Many studies have been developed related to the production of $\mathrm{CBM}$, and this paper discusses several characteristics, patterns and techniques regarding the production of methane gas from coal through the use of a sacrifice well. Several scenarios are analysed with the use of a simulator. The results show that the production of a thick CBM reservoir, with some sensitivity patterns of production through the use of a sacrifice well, have an influence on the production of gas and water for the exploitation of CBM resources. In other words, the use of new techniques that are discussed in this paper have an impact on reducing the dewatering time and are effectively implemented in Indonesia, which has thick CBM formations.
\end{abstract}

Keywords: CBM Thick Formation, Sacrifice Well, CBM Production Patterns Sensitivity

\section{Introduction}

Energy is a primary need of living things. Rapid technological developments have led to the use or consumption of significantly increasing amounts of energy. Besides, the availability of energy within a country has a strong impact on determining the development of the country. Oil and natural gas have become one of the more preferred energy sources, for many reasons including that their use is instantaneous, easy to store, the level of hazard is relatively low compared to other sources such as nuclear, and that they are relatively abundant in various regions of the world. However, in recent decades oil and gas resources have declined in production in many parts of the world due to the increasing scarcity of giant reservoir resources. This is very much in contrast to the increasing demand for energy, forcing companies to find oil and gas reservoirs to compensate for this. One solution to achieve this involves the development of unconventional hydrocarbon resource exploitation. Unconventional hydrocarbons are obtained from reservoirs with different characteristics compared to conventional reservoirs. This paper focusses on gas phase hydrocarbon resources, particularly targeting unconventional natural or reservoir gases.

Unconventional natural gas has various types. CBM is one such unconventional natural gas. CBM is the result of methane gas obtained from coal. The potential of CBM is significantly large. The amount of world reserves is very promising, at an estimated 13.311 million tons. Indonesia has $11 \mathrm{CBM}$ basins located in Sumatra, Kalimantan, Java and Sulawesi. The largest CBM basin is found in Sumatera, with a methane content of approximately $183 \mathrm{TCF}$ and a concentration of $24.9 \mathrm{BCF} / \mathrm{m} 2$. In the Asia-Pacific region, Indonesia is the largest coal producer, with 123.6 million tons in 2006 and with coal resources of around 38.8 million tons (Ekawan et al, 2006). Thus, Indonesia has significant potential in terms of exploitation of CBM resources. It is estimated that Indonesia has CBM resources of 450 TSCF (Abdassah, 2007), making it the 6th largest CBM-containing country in the world after Russia, Canada, China, the USA and Australia. 
With the potential of this vast resource, the development of CBM resources in Indonesia should be encouraged. But in reality, the development of CBM has been quite slow. Factors associated with this include regulations governing the exploitation of resources in Indonesia, with the government not adequately supporting CBM development, and some technical factors that accompany production. Besides, unlike conventional gas energy, $\mathrm{CBM}$ at the beginning of production produces significant amounts of water for a certain period of time during the dewatering process to obtain methane adsorbed on the coal surface. During this process, large-scale investment is needed to increase the number of wells and water countermeasures, while there is no methane production within a certain period of time. With little development of production techniques to reduce gas production time and dewatering duration, the interest of investors or government in developing CBM resources has so far tended to be low. Thus, many studies have been carried out on the techniques of resource development in terms of production techniques, reservoir engineering, drilling, completion engineering and other techniques that run more effectively and efficiently and have economic value that will captivate the interests of investors.

The objectives of this study are: (1). Define the fluid production rate characteristics based on a certain thickness, (2). Determine effective well production patterns applied to thick formations, (3). Determine the effective production pattern of the well in accelerating the dewatering time on thick formations, (4). Determine effective production patterns so that gas production can be done as quickly as possible on thick formations.

Indonesia's CBM reservoir tends to be thick, ranging between 18-111 ft. (Stevens and Hadiyanto, 2004), encouraging authors to conduct further studies through simulations related to effective and efficient production patterns in the production of CBM from thick reservoirs. Therefore, this paper will discuss the characteristics of CBM reservoirs of a certain thickness and how effective and efficient production patterns are in exploiting it. In this study, an analysis of the results of the $\mathrm{CMG} \mathrm{GEM}^{\mathrm{TM}}$ numerical simulator was used and a simulation was conducted for 15 years from January 1, 2015 to January 1, 2030. Based on the simulation results, a comparison and analysis of simulations from various production scenarios related to evaluation against thickness was conducted. Furthermore, a case analysis was carried out, the results of which are particularly influential in the context of CBM.

\section{Method}

CMG-GEM $^{\mathrm{TM}}$ numerical simulator was used and the simulation was conducted for 15 years from January 1 , 2015 to January 1, 2030. Based on the simulation results, the comparison and analysis of simulation results from various production scenarios related to evaluation against thickness.

\subsection{Coalbed Methane (CBM)}

Coalbed methane (CBM), is a natural gas (hydrocarbon) with methane as the main component that occurs naturally in the process of coalification in trapped conditions and is absorbed in coal seams. The process of CBM formation comes from highly organic plant material, through several chemical and physical processes (in the form of constant heat and pressure) that turns into peat and eventually forms coal. CBM is a non-conventional hydrocarbon gas sourced from coal, and is stored in a coal reservoir. Such reservoirs are generally very different from oil reservoirs. CBM or coalbed gas is stored due to adsorption in a coal micropore. The gas is also called sweet gas because there is no $\mathrm{H} 2 \mathrm{~S}$ content. CBM is stored in the rock through a process called adsorption. Methane attaches to a micropore of coal (matrix). Fractures in the coal may also contain free or water-saturated gases. This system is called Dual Porosity Reservoirs.

CBM is produced by firstly engineering coal as a reservoir to obtain enough space as a methane gas exit. The engineering process begins with producing water (dewatering) in order to change the balance of mechanics. After the pressure drops, coal gas will come out of the coal matrix. Methane then flows through the fracture of coal and finally out to the wellbore. The peak of CBM production varies from 2 weeks to 7 years, while the production decline period is slower than for conventional gas. Production of CBM has many purposes, including that it can be sold directly as natural gas, and can be used as energy and for industrial raw materials. CBM production is strongly influenced by fracture system, fracture spacing and fracture connection. The porosity and permeability of the fracture causes the gas to be produced into the wellbore. Initially the system is at equilibrium, the cleats are usually saturated by $100 \%$ water and the gas is stored in a matrix whose water cannot enter it, even if there is usually in the matrix of 1-5\% (Nikola Marinic, 2004 ). Therefore, in order to produce gas, water must be produced from coal to lower reservoir pressure.

It is important to note that the behavior of the CBM production curve is very different from the conventional reservoir production curve. The early stages of gas production are strongly influenced by the production of water in the fracture of the reservoir, which also controls the flow of fluid into the well. The water in the reservoir must first be produced to lower the reservoir pressure, in order to create a pressure difference between matrix and 
fracture.

Stages of methane production process for CBM production:

\section{A. Stage 1}

This initial stage is characterized by constant water production rates, with reservoir pressures beginning to decline. During this phase, wells are pumped to increase the gas production rate. Usually the gas rate will increase, depending on the relative permeability around the drill hole.

\section{B. Stage 2}

This phase is characterized by negative decline or drastic reduction in water production rate. At this stage, the flow is in a dynamic state (constantly changing) depending on the relative permeability of water and gas, the outer boundary effect begins to flow (the flow is in a pseudo steady state) and then the flow becomes dynamic.

\section{Stage 3}

This stage begins when the flow conditions in the reservoir begin to stabilize, the well has reached the peak gas rate, and gas production shows a declining trend. During this stage, water production is low and water and gas permeability becomes small, with the flow remaining in a pseudo steady state.

Objectively, the stage of CBM flow itself in the production process is also divided into 3 stages, namely:

1. Desorption of methane from micropores of coal. Desorption is possible by decreasing the reservoir pressure through the dewatering process.

2. When the reservoir pressure drops to the desorption pressure, methane diffuses into the matrix until it reaches the fracture.

3. After reaching the fracture, methane will flow, and enter into the wellbore and be produced at the surface.

\subsection{Langmuir-Isotherm Adsorbtion Curve}

Isotherm adsorption is a measure that expresses the ability of coal to absorb methane at a given pressure in a fixed temperature state. This information is needed to predict the methane released due to decreased pressure during production. Capacity of coal absorption depends on several aspects such as coal quality, temperature, moisture content of coal matrix, and pressure. At low pressure, the absorption capacity increases almost linearly with pressure. As the pressure continues to accelerate, the ability of coal to absorb methane is reduced, reaching a certain pressure where very little additional gas can be absorbed. The higher the quality of the coal, with a larger surface area, the higher the coal absorption capacity.

The methane storage mechanism for CBM tends to be more dominant for adsorption gas compared to free gas. CBM production in coal will require a decrease in pressure to allow gas desorption from the matrix surface, so that methane can then flow through the cleats to the borehole. The adsorption-desorption mechanism can be illustrated by the Langmuir Isotherm equation, i.e. by conducting laboratory tests on coal samples to determine the adsorption capacity at various pressures and the same temperature. From the Langmuir Isotherm curve, we know the reservoir characteristics for the maximum adsorption capacity at a given pressure as a reference of the minimum pressure of desorption and production mechanisms. Figure 1 shows the typical curve of Langmuir-Isotherm and Equation 1 depicts the gas adsorption equation.

The gas adsorption equation (Langmuir, 1918) can be written as follows:

$$
G_{S}=\frac{V_{L} P}{P_{L}+P}
$$

Where:

Gs = Gas storage capacity, SCF / ton

$\mathrm{P} \quad=$ Pressure, psia

$\mathrm{VL}=$ Langmuir Volume constant, $\mathrm{SCF} /$ ton

$\mathrm{PL}=$ constant Langmuir pressure, psi

From the results of experimental desorption tests on coal samples, initial pressure and volume are obtained. The results are then plotted on the Langmuir Isotherm curve to determine the condition of the coal reservoir. If the result of the desorption test plot shows the point under the Langmuir curve, then the coal reservoir is in an under-saturated condition, i.e. the capacity of the adsorption gas is not at a maximum due to mixing with the water as the coalification product. In under-saturated conditions, a pressure drop is required to allow the 
desorption mechanism of the gas from the matrix surface and the gas to be produced, so that it flows through the cleats to the borehole. Pressure reduction is performed by dewatering, which involves draining the water in the coal reservoir. The dewatering process lasts for several months to several years, depending on the level of maturity and water content of the results of coalification.

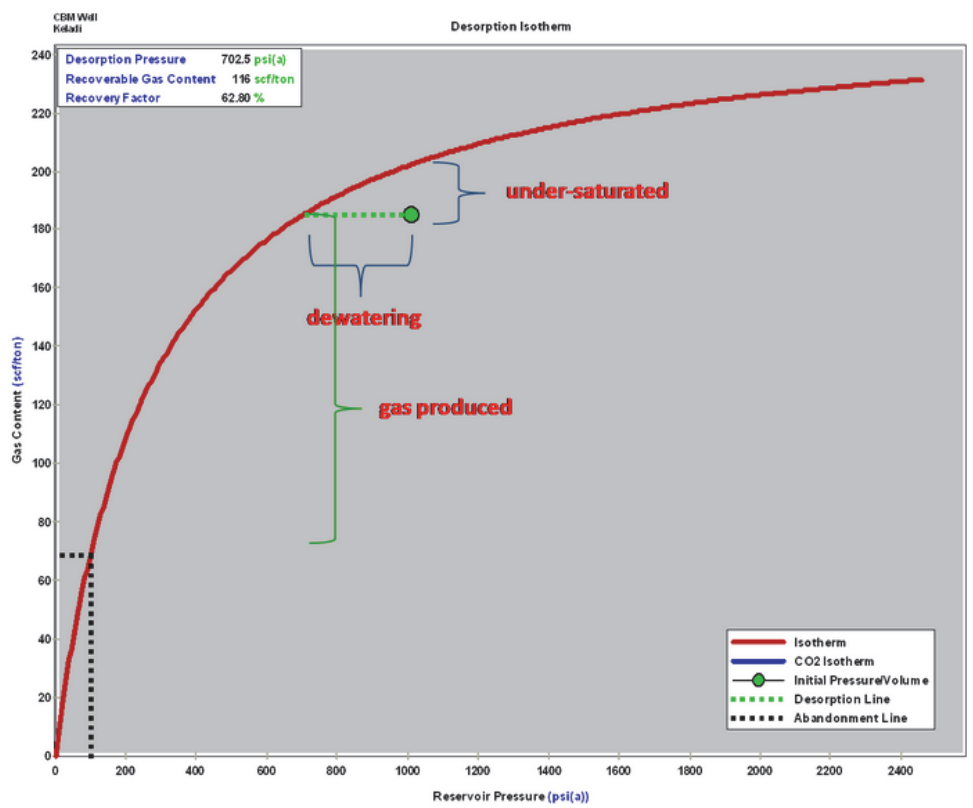

Figure 1. The typical curve of Langmuir-Isotherm (Abdassah, 2012)

\subsection{CBM Reservoir Model}

The CBM reservoir simulation model in this study used a type of Dual Porosity model, with a total grid of 2,250 grid blocks with a specification of $15 \times 15 \times 10$ (i x j x k configuration). The dual porosity model applied in this study is the Warren and Root shape factor model. In this CBM reservoir model, evaluation and comparison between several scenarios are expected to provide effective and efficient results in accelerating the dewatering time in the thick CBM reservoir.

There are 3 types of CBM reservoir evaluated. All three types of CBM reservoir models have the same model specifications, but differ only in reservoir thickness. The three models have thicknesses of $50 \mathrm{ft}$., $100 \mathrm{ft}$., and 150 ft., respectively. In these three reservoirs, some optimum scenarios were applied and then the results were compared to evaluate the production characteristics for different thicknesses. The basic assumptions are:

1. The absence of aquifer flow to the reservoir

2. The Langmuir Isotherm curve is constant in value on each model grid

3. The hydrocarbon gas component in the fluid model is composed of $100 \%$ methane without moisture or ash

4. The permeability and porosity of the reservoir are homogeneous at all reservoir layers.

Table 1 contains information on the parameters used in the CBM reservoir model. Table 2 presents rock, fluid and well parameters, while Table 3 shows Langmuir parameters used in the CBM reservoir model. Figure 2 shows Langmuir model used in the model.

Table 1. Reservoir parameter characteristic

\begin{tabular}{ll}
\multicolumn{1}{c}{ Parameter } & \multicolumn{1}{c}{ Value } \\
\hline Area (acres) & 180 \\
Depth (ft) & 2000 \\
Thichness (ft) & $50 ;$ \\
& $100 ;$ \\
& 150 \\
\hline
\end{tabular}




\begin{tabular}{ll}
\hline Model Dimension & $\begin{array}{l}15 \times 15 \times 10 \\
(2250 \text { blok grid })\end{array}$ \\
Porosity of matrix & 0,001 \\
Porosity of cleats & 0,02 \\
Permeability of & $\mathrm{i}=0,001$ \\
matrix (i,j,k), (md) & $\mathrm{j}=0,00025$ \\
& $\mathrm{k}=0,0005$ \\
Permeability of & $\mathrm{i}=10$ \\
cleats (i,j,k) (md) & $\mathrm{j}=2,5$ \\
& $\mathrm{k}=5$ \\
Cleat spacing (inch) & 2 \\
\hline
\end{tabular}

Table 2. Rock, Fluid, and CBM well parameters

\begin{tabular}{lc}
\hline \multicolumn{1}{c}{ CBM Reservoir Parameters } & Value \\
\hline Water saturation-cleat & 1 \\
Reservoir Temperature $\left({ }^{\circ} \mathrm{F}\right)$ & 104 \\
Water Viscosity $(\mathrm{cp})$ & 0,607 \\
Water Density $\left(\mathrm{lb} / \mathrm{ft}^{3)}\right.$ & 62,48 \\
Reference pressure for air & 14,7 \\
density (psi) & 91 \\
Coal Density (lb/ft & \\
Coal Compressibility (1/psi) & $1.01353 \mathrm{e}-006$ \\
Pressure Reference for Coal & 14,69 \\
Density (psi) & \\
Bottom hole pressure (psi) & 100 \\
Well Radius (ft) & 0,25 \\
\hline
\end{tabular}

Table 3. Langmuir-Isothermal Parameter

\begin{tabular}{|c|c|}
\hline Langmuir-Isothermal Parameters & Value \\
\hline $\begin{array}{l}\text { Maximum } \mathrm{Gc} / \quad \text { constants } \\
\text { Langmuir, } \mathrm{V}_{\mathrm{L}}(\mathrm{SCF} / \text { ton })\end{array}$ & 250 \\
\hline Langmuir Pressure Constants, $\mathrm{P}_{\mathrm{L}}$ (psi) & 150 \\
\hline Coal Desorption Time (days) & 10 \\
\hline Initial Gas Composition & 1 \\
\hline Initial Gas Content (SCF/ton) & 220 \\
\hline $\begin{array}{l}\text { Pressure Equilibrium in Initial Gas } \\
\text { Content (psi) }\end{array}$ & 1100 \\
\hline
\end{tabular}

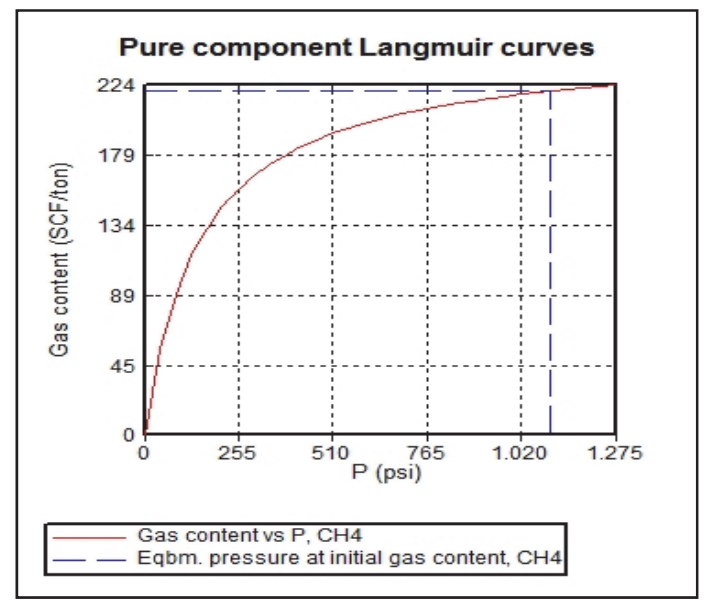

Figure 2. Langmuir-Isotherm curve model 


\section{Results}

The objective of this study is to determine the most effective and efficient CBM production pattern, with the aim of decreasing the dewatering time, and because of that we propose a solution - that is, by applying a sacrifice well. Before discussing the application of such a well, it should be noted that the use of one production well in the dewatering time phase is less effective. Figure 3 shows CBM reservoir model with one producing well. Curve shown in the figure 4 , shows that the gas gain in the dewatering time phase is very small. In contrast, the production of gas at a relatively fast rate and in large amounts is needed to offset the investment costs provided in the development and exploitation of CBM resources - for that, we will need significant technical development to take place.

One such development is the use of a so-called "sacrifice well". This involves the use of several wells at specific locations in the reservoir, which allows production of water (as the victim well) as soon as possible, with the basic principle that through the procurement of this well, the water at macro fracture reservoir CBM will be more rapidly produced. Thus, the gas absorbed in the micropore will be more quickly produced through other wells that are not sacrifice wells, so that other wells (gas producer) can focus on producing gas with good production performance. In the presence of this sacrifice well, a reservoir can already be produced from a gas production well (i.e. a well that is not a sacrifice well) in a relatively rapid timeframe. To perform a simulation of the performance of this sacrifice well, we carry out an analysis and evaluation of those scenarios that give the best performance. In total, there are 5 parts of the evaluation conducted to achieve the objectives of this study.

\section{$3.11^{\text {st }}$ Scenario (Base Case)}

In this scenario, a comparison of 2 types of wells is assumed to provide good performance as well candidates to be selected as a sacrifice well. Both wells are intended to be horizontal and vertical. Both types of wells will be applied to CBM reservoirs that have been modeled, and the performance of both will be compared to each other based on water and gas rate parameters for each condition. Because the reservoir model tends to be large (180 acres), the horizontal well is given 3 wells to compensate for the reservoir, while vertical wells are given 6 wells spread over a simulated CBM reservoir (this can be seen in the drawings and attachments). Based on the simulation results, analysis and evaluation of the two different conditions, the final reservoir is produced with 6 vertical and 3 horizontal wells. The characteristics and properties of the reservoir are equal for both cases. As mentioned previously, the purpose of this scenario is to compare the performance of the two cases, so that the case with the best production performance can be selected to be a sacrifice well and applied to subsequent scenarios, so this case is made as a base case. The parameters for determining the best sacrifice well are the water and gas rates and dewatering time for both conditions, and this parameter can be observed from the simulation result of the curve. From the intended simulation results, the performance of the two cases is illustrated in the following figure 5 and figure 6 :

Gas Saturation - Fracture 2018-01-01

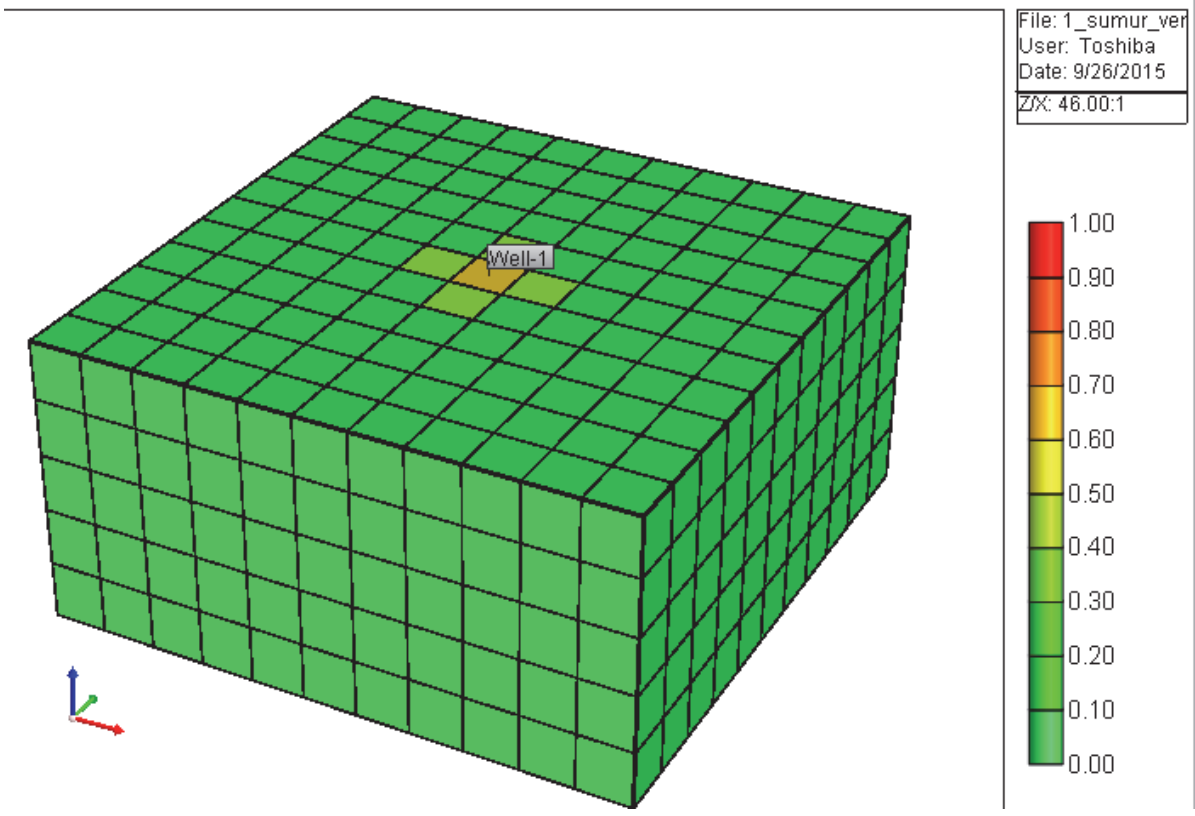

Figure 3. CBM Production by using 1 production well 


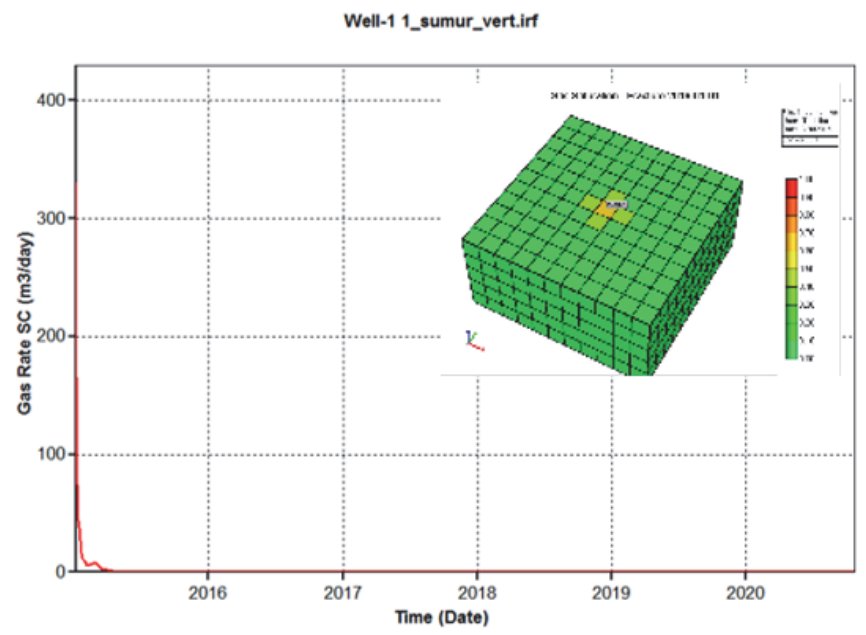

Figure 4. The Gas Rate Performance in CBM production by using 1 production well

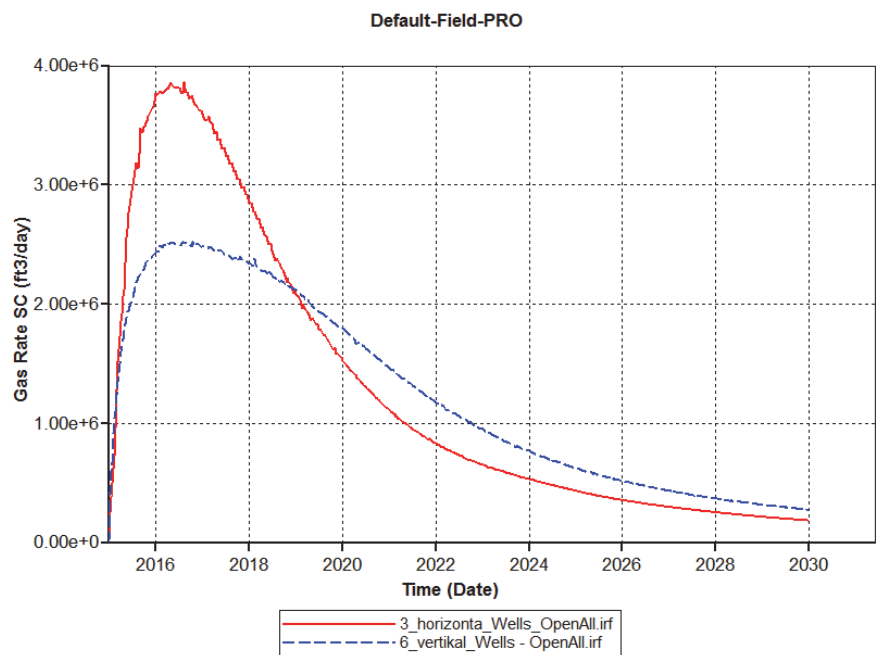

Figure 5. Gas rate performance for scenario 1

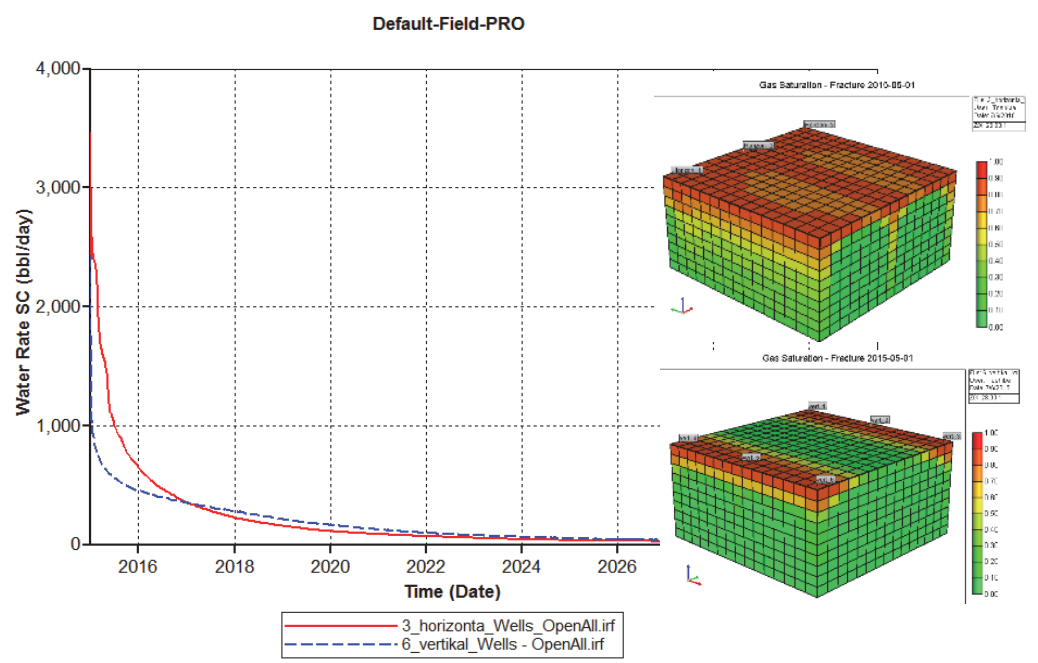

Figure 6. Water rate performance for scenario 1 
It should be underlined that the selection of a sacrifice well in this case is based on the ability or performance of the best wells to produce water, so that the ultimate goal of producing gas as soon as possible can be realized. In other words, the use of a sacrifice well is needed to support the performance of a special well (wells other than a sacrifice well) which will produce gas, then the need to evaluate the most effective and efficient selection of the sacrifice well based on the parameters that have been made. On that basis, through the simulation results run in scenario 1, it can be observed that the production case in the CBM reservoir with the use of 3 horizontal wells tends to be better than 6 vertical wells. This can be seen in the following table 4 .

Table 4. The comparison of cases in scenario 1

\begin{tabular}{lll}
\hline \multicolumn{1}{c}{ Parameters } & 6 vertikal wells & 3 horizontal wells \\
\hline Field peak gas rate & $2,5 \times 10^{6} \mathrm{ft}^{3} / \mathrm{day}$ & $3,84 \times 10^{6} \mathrm{ft}^{3} / \mathrm{day}$ \\
Field initial water rate & $2072,9 \mathrm{bbl} / \mathrm{day}$ & $3468,8 \mathrm{bbl} / \mathrm{day}$ \\
Dewatering time & $\mathbf{6 5 4 , 5}$ day & 477,7 day \\
\hline
\end{tabular}

Based on the table, it is clear that the conditions of 3 horizontal wells tend to be more productive. This is quite logical if it is remembered that water tends to prefer the state of downward production, due to the influence of gravity, so that water is quickly produced in large quantities in the case of 3 horizontal wells. This is in contrast to production conditions using vertical wells, where water production tends not to be assisted by gravitational forces. Therefore, because the parameters of gas and water rates in the case of 3 horizontal wells are better, the selection of a sacrifice well is aimed at the use of 3 horizontal wells.

\section{$3.22^{\text {nd }}$ Scenario (Sensitivity Test Performance of Sacrifice Well with 3 Different Thickness)}

In this scenario, an evaluation of the effect of thickness on the performance of the sacrifice well has been performed so that the characteristic of gas and water production on thickness can be known. Each thickness tested involved installation of 3 horizontal wells to the reservoir CBM (with the same characteristic of reservoir) with a thickness of $50 \mathrm{ft}$., $100 \mathrm{ft}$., and $150 \mathrm{ft}$. As mentioned previously, the purpose of this case is to determine the characteristic of fluid production with 3 different thicknesses. The result of this scenario can be seen in the table 5 .

Table 5. Result from scenario 2

\begin{tabular}{llll}
\hline \multicolumn{1}{c}{ Parameters } & $\mathbf{5 0} \mathbf{f t}$ thickness & \multicolumn{1}{c}{$\begin{array}{c}\mathbf{1 0 0} \mathbf{f t} \\
\text { thickness }\end{array}$} & \multicolumn{1}{c}{$\begin{array}{c}\mathbf{1 5 0} \mathbf{f t} \\
\text { thickness }\end{array}$} \\
\hline Field peak gas rate & $3,84 \times 10^{6} \mathrm{ft}^{3} /$ day & $1,1 \times 10^{7} \mathrm{ft}^{3} /$ day & $1,48 \times 10^{7} \mathrm{ft}^{3} /$ day \\
Field water rate pada peak gas rate & $493 \mathrm{bbl} /$ day & $982 \mathrm{bbl} /$ day & $1335,5 \mathrm{bbl} /$ day \\
Dewatering time & 517 day & 627 day & 723 day \\
\hline
\end{tabular}

Based on table 5, it can be seen that the thicker the CBM reservoir, the higher the gas rate through the sacrifice well. Besides, the thicker the CBM reservoir, the higher the water rate, although dewatering time will be much longer. This case is supported by the fact that as the CBM reservoir with the same characteristic becomes thicker, the fluid reserve contained in macropores and micropores will be higher. In other words, the potential of the CBM reservoir for production with a sacrifice well will be higher if the thickness is increased, because gas and water rates will be higher. However, the main focus is to determine the better production techniques so that gas rate can be maximized and water rate can be minimized. Based on scenario 2's results, the idea to carry out scenario 3 was developed.

\section{$3.33^{\text {rd }}$ Scenario (Test of Sacrifice Well Performance Sensitivity Plus Gas Producer Wells in 3 Different Thickness Types)}

This scenario is essentially similar to the previous scenario 2 . The difference is the addition of 1 well (which can be seen in Figure 7) which is focused on produce gas production. In addition, in this scenario, the effect of thickness on gas and water rates on the surface of the special well mentioned above (vertical well right in the center of the reservoir) was evaluated. This well will act as a gas producer, because the well is opened at a 
different time than the opening of the sacrifice well ( 3 horizontal wells), or in other words the well is only opened after the sacrifice well operates for several months, and since its position is in the top reservoir, this well will then specifically produce gas.

As mentioned previously, the purpose of this scenario is to evaluate the combination performance of 3 horizontal wells acting as a sacrifice well, and 1 vertical well on the reservoir - the latter scenario also analyzed its effect on 3 types of thickness. The results are shown in table 6 .

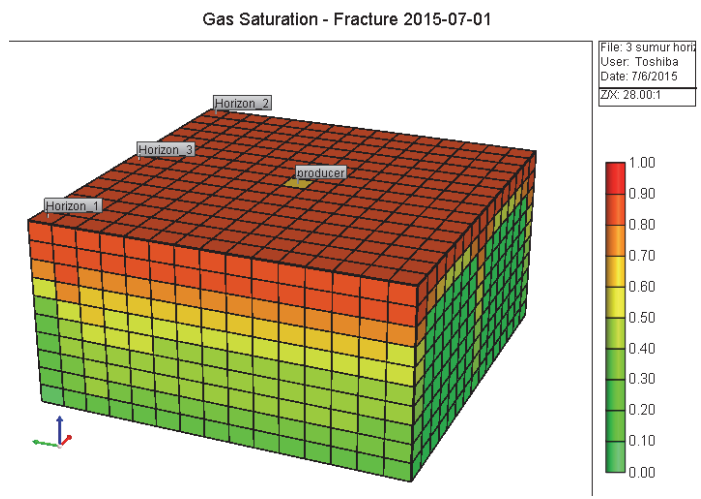

Figure 7. Gas producer well profile at scenario 3

Table 6. Result from Scenario 3

\begin{tabular}{llll}
\hline parameters & $\begin{array}{l}\mathbf{5 0} \mathbf{f t} \\
\text { thickness }\end{array}$ & $\begin{array}{l}\mathbf{1 0 0} \mathrm{ft} \\
\text { thickness }\end{array}$ & $\begin{array}{l}\mathbf{1 5 0} \mathrm{ft} \\
\text { thickness }\end{array}$ \\
\hline Field peak gas rate & $4,04 \times 10^{6} \mathrm{ft}^{3} /$ day & $1,1 \times 10^{7} \mathrm{ft}^{3} /$ day & $1,48 \times 10^{7} \mathrm{ft}^{3} / \mathrm{day}$ \\
Field water rate at peak gas rate & $534 \mathrm{bbl} / \mathrm{day}$ & $1137 \mathrm{bbl} /$ day & $1401 \mathrm{bbl} /$ day \\
Dewatering time & $486 \mathrm{day}$ & $547 \mathrm{day}$ & $700 \mathrm{day}$ \\
Producer water rate & $1,8 \mathrm{bbl} /$ day & $7,1 \mathrm{bbl} / \mathrm{day}$ & $13,5 \mathrm{bbl} / \mathrm{day}$ \\
Producer gas rate & $0,3 \times 10^{6} \mathrm{ft}^{3} /$ day & $0,9 \times 10^{6} \mathrm{ft}^{3} /$ day & $1,3 \times 10^{6} \mathrm{ft}^{3} /$ day \\
\hline
\end{tabular}

These results indicate that with respect to the producer well, the gas rate increases and the amount of gas from this well is sufficient. One further advantage is that for the producer well, the water rate is very low, ranging only in some units of bbl. / day. This suggests that at the top of the CBM reservoir over a period of a few months (in this case 5 months), since the opening of the sacrifice well can already be produced, and the fluid is predominantly methane with very little water production. Based on results obtained for scenario 3 , an additional scenario is needed to optimize gas production at the top reservoir, so that the resulting gas rate is higher. This is achieved in the next scenario.

\section{$3.44^{\text {th }}$ Scenario (Analysis and Evaluation of the Best Production Well Gas Pattern Selection)}

This scenario evaluated and analyzed the pattern of the production well which would give the highest gas rate, but with the smallest water rate possible. In this scenario, there are several cases tested, including 2 horizontal wells in the form of a cross ( $\mathrm{x}$ ) and 2 horizontal wells in the form of a crossed upright $(\mathrm{T})$. The profile of each case is depicted at Figure 8. After being evaluated and analyzed, there were two main options in the installation of the top reservoir well. The selection was determined based on the fact that horizontal wells will be much more effective in sweeping the CBM reservoir area, which generally spread like a carpet. Thus, we need further evaluation of the horizontal well's pattern which is suitable for application. From 2 well pattern candidates that were run, which were $\mathrm{X}$ and $\mathrm{T}$ patterns, an evaluation was carried out based on the fulfillment of existing parameters. A comparison is given in table 7. 


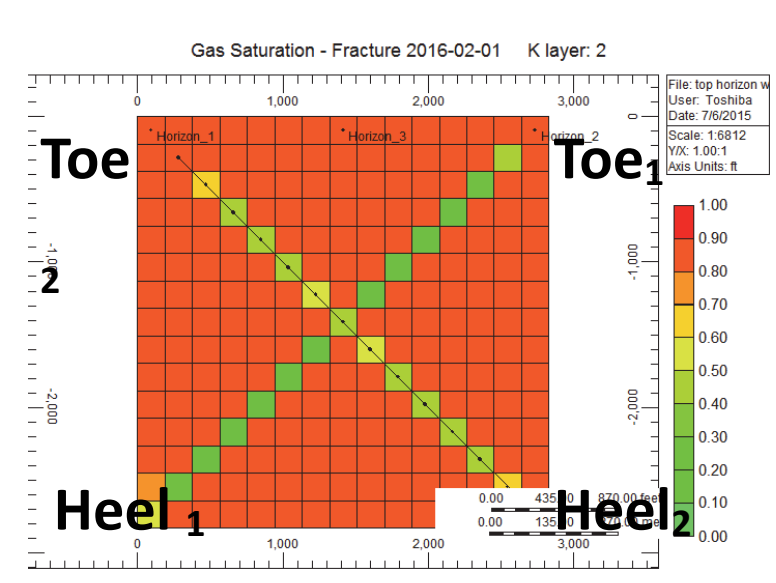

(a) Top horizontal well (X)

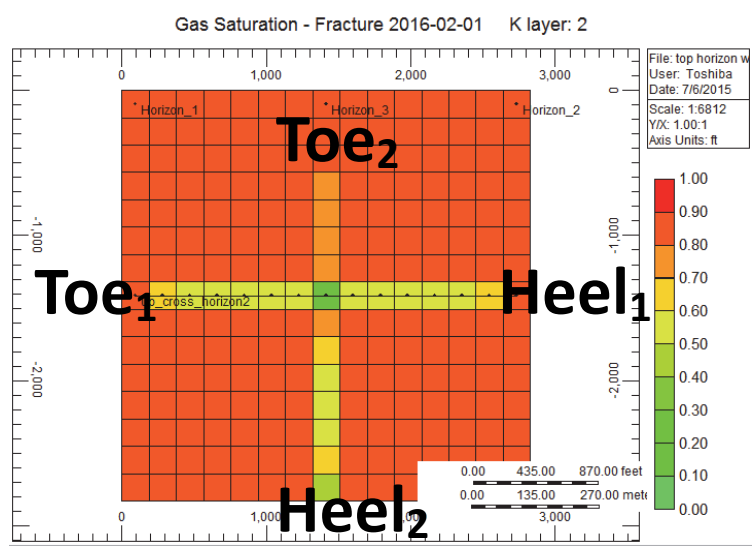

(b) Top horizontal well (T)

Figure 8. Well Configuration for scenario 4

Tabel 7. Result of scenario 4

\begin{tabular}{lll}
\hline \multicolumn{1}{c}{ parameters } & Top horizontal well $(\mathbf{X})$ & Top horizontal well $(\mathrm{T})$ \\
\hline Field peak gas rate & $6,34 \times 10^{7} \mathrm{ft}^{3} /$ day & $7,3 \times 10^{7} \mathrm{ft}^{3} /$ day \\
Field water rate pada peak gas rate & $589 \mathrm{bbl} /$ day & $746 \mathrm{bbl} /$ day \\
Gas rate (well) & $3,4 \mathrm{ft}^{3} /$ day & $4,7 \mathrm{ft} / \mathrm{day}$ \\
Water rate (well) & $103 \mathrm{bbl} /$ day & $70 \mathrm{bbl} /$ day \\
Dewatering time & $348 \mathrm{day}$ & $392 \mathrm{day}$ \\
Producer water rate & $87 \mathrm{bbl} /$ day & $44 \mathrm{bbl} /$ day \\
\hline
\end{tabular}

Based on the tabulation, it can be seen that the top horizontal well (T) has the best performance. This is concluded from the fact that gas rate of both field and well are greater than the top horizontal well X. This may be influenced by the value of porosity and permeability in the $\mathrm{x}$ and $\mathrm{y}$ axes (I and J). If the permeability and porosity value is large, then the water will tend to fill it so that more water will fill macropores of the CBM reservoir. Although well $\mathrm{X}$ is able to reach a larger area of well $\mathrm{T}$, in fact the performance of well $\mathrm{T}$ is better when compared based on gas rate. On these observation, the pattern selection from scenario 4 is therefore a top horizontal well (T) pattern.

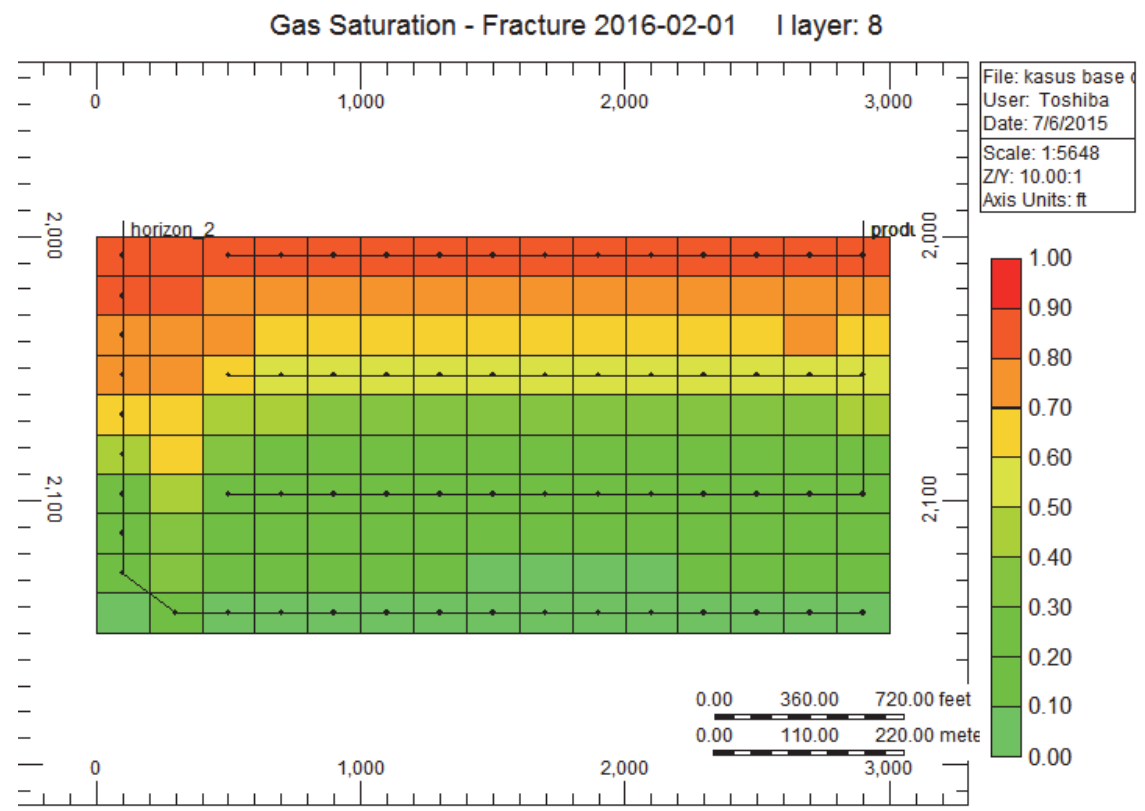

Figure 9. Profile of 3 different depth horizontal wells and 3 sacrifice wells 


\section{$3.55^{\text {th }}$ Scenario (Analysis and Evaluation of the Scenario to Determine the Depth Characteristics of Gas Well Production)}

This scenario aims to apply several deep horizontal wells of different depths, but still in the same reservoir that has a thickness of $150 \mathrm{ft}$. This is done to evaluate the characteristics or phenomena of water and gas production behavior at several thickness levels, therefore the effective production techniques can be planned in producing methane from the reservoir. Figure 9 illustrates the reservoir and well profile.

Based on the objective to determine the characteristics of CBM production in thick reservoirs, this scenario is used to analyze the well production performance if it is arranged within a certain depth range but still within 1 reservoir. This scenario certainly applies to the sacrifice well at the bottom of the reservoir. The results can be seen in table 8 .

Table 8. Result of scenario 5

\begin{tabular}{|c|c|c|c|}
\hline Parameter & $\begin{array}{l}35 \mathrm{ft} \text { thickness (from the } \\
\text { top of reservoar) }\end{array}$ & $\begin{array}{c}70 \mathrm{ft} \text { thickness (from the } \\
\text { top of reservoar) }\end{array}$ & $\begin{array}{c}105 \mathrm{ft} \text { thickness (from the } \\
\text { top of reservoar) }\end{array}$ \\
\hline Gas rate (well) & $1,15 \times 10^{7} \mathrm{ft}^{3} /$ day & $6,71 \times 10^{6} \mathrm{ft}^{3} /$ day & $2,92 \times 10^{6} \mathrm{ft}^{3} /$ day \\
\hline Water rate (well) & $49 \mathrm{bbl} /$ day & $670 \mathrm{bbl} /$ day & $821 \mathrm{bbl} / \mathrm{day}$ \\
\hline Dewatering time & 319 day & 609 day & 1035 day \\
\hline
\end{tabular}

Thus, it can be observed that the deeper the wells are installed from the top of the CBM reservoir, the smaller the gas rate will be, inversely proportional to the water rate, and the deeper the wells are from the top reservoir, the greater will be the water rate. Similarly, with respect to the dewatering time, the deeper the wells are from the top reservoir, the longer the dewatering time will be. Considering that at the bottom of the reservoir a sacrifice well is installed, then this will significantly affect and support the above results. In other words, the closer a well production is to a sacrifice well in the same CBM reservoir, the greater the water rate and dewatering time will be, while the gas rate will be smaller. It is therefore strongly recommended that if the production of CBM uses a sacrifice well, then the production well used to produce the gas should be fitted far enough away (and if possible installed at the top of the reservoir), in order to obtain effective and efficient results.

\section{Discussion}

Based on the simulation result done on various sensitivities of CBM production patterns through sacrifice wells, hence can be concluded that the application of 3 horizontal wells at the bottom of the well is much more effective and efficient as a sacrifice well as well as production well from a technical point of view than the application of 6 vertical wells. The thicker a reservoir CBM, the gas rate will be and due to the influence of gravity, the faster the gas out of the CBM surface so that gas production is relatively easy. The thicker a reservoir CBM then the water rate on the sacrifice well and production well will be bigger, and dewatering time will also be longer. The use of wells at the top of the CBM reservoir and the opening of wells with different time with the opening of the sacrifice well will assist in accelerating the gas production that tend to have a low water content and also higher rate of gas. The application of two horizontal (T) wells is more effective and efficient in producing gas from technical point of view than the application of 2 cross horizontal wells (x). If a CBM well production uses sacrifice well at bottom reservoar, it is advisable to install a production well that is far enough from sacrifice well. And if possible, production well is installed on top reservoir only.

\section{Acknowledgments}

We would like to thank P3MI research fund from Institut Teknologi Bandung for funding the research.

\section{References}

Abdassah, D. (2007). Kuliah Teknologi CBM. Bandung: Institut Teknologi Bandung.

Abdassah, D. (2013). Pembuatan Pedoman Cadangan Unconventional Gas dan Revisi Pedoman Cadangan Panas Bumi Pertamina. Bandung, ITB. LAPI-ITB.

Aminian, K., Coalbed Methane - Fundamental Concepts, West Virginia University.

Arif, A. (2015). Analisis dan Strategi Pola Sumur Produksi pada Reservoir Datar Coalbed Methane (Cbm) terhadap Komunikasi Aquifer, ITB, 1-7.

Craft, B. C., \& Hawkins, M. F. (1990). Applied Petroleum Reservoir Engineering, Prentice Hall PTR. 
Ertekin, T. (2007). Reservoir Engineering of Coalbed Methane Reservoir, Pennsylvania State University, Session 4.

Halliburton. (2007). Coalbed Methane: Principle and Pratices, Halliburton Company.

Kartiningrum, U. (2012). Pengaruh Well Spacing dan Cleat Spacing Terhadap Recovery Factor Pada Reservoir Coalbed Methane (CBM) Dengan Komunikasi Akuifer, ITB, 1-5.

Kim, K. H., et al. (2012). The Effect of Aquifer Condition on Methane Recovery for $\mathrm{CO}_{2}$ Injection on Coaobed, SPE 153518.

LEMIGAS. (2012). Gas Metana Batu Bara Energi Baru Untuk Rakyat, Jakarta, LEMIGAS.

Permadi, A. K. (2004). Diktat Teknik Reservoir II, Teknik Perminyakan ITB.

SPE. (2015). Water influx models. Retrieved from http://petrowiki.org/Water_influx_models

SPE. (2015). Waterdrive reservoirs. Retrieved from http://petrowiki.org/Waterdrive_reservoirs

Trisnadi, M. A. (2013). A Study to Develop Predictive Model of Dewatering Time of Coalbed Methane (CBM) Production for Horizontal Well, ITB, 1-6.

\section{Symbol}

$\mathrm{G}_{\mathrm{C}} \quad=\mathrm{CBM}$ Gas Content, $\mathrm{SCF} /$ ton

$\mathrm{V}_{\mathrm{L}} \quad=$ Langmuir Volume, $\mathrm{SCF} /$ ton

$\mathrm{P}_{\mathrm{L}} \quad=$ Langmuir Pressure, $\mathrm{psia}$

$\mathrm{k} \quad=$ Permeability, $\mathrm{mD}$

$\varnothing \quad=$ Porosity, fraction

$\mathrm{P} \quad=$ Pressure, $\mathrm{psia}$

$\mathrm{V}$ = Langmuir Volume Constant,SCF/ton

\section{Copyrights}

Copyright for this article is retained by the author(s), with first publication rights granted to the journal.

This is an open-access article distributed under the terms and conditions of the Creative Commons Attribution license (http://creativecommons.org/licenses/by/4.0/). 